\title{
Propriedades físicas e de fluxo de produtos granulares para projeto de silo
}

\author{
Physical and flow properties of granular products for sillo design \\ Propiedades físicas y de flujo de productos granulares para el diseño de silos
}

\section{Resumo}

O conhecimento das propriedades físicas e de fluxo dos produtos a se armazenar são fundamentais para determinação do tipo de fluxo em silos, tremonhas e transportadores, possibilitando manuseio e processamento adequados do produto, de tal modo que se obtenha uma estrutura econômica, segura e com durabilidade, assumindo elevado interesse no Brasil pelo fato do país não possuir norma de dimensionamento e projeto dessas estruturas. Buscou-se neste trabalho contornar essa limitação pela determinação das propriedades físicas e de fluxo de dois produtos agrícolas expressivos nacionalmente (grãos de milho e trigo) que poderão ser inseridas em uma futura norma brasileira de ações e fluxo em silos. Na obtenção dos dados, foi utilizado o aparelho de cisalhamento direto por translação (TGS 70-140) e duas superfícies de parede: aço liso e rugoso, por serem os materiais com maior possibilidade de uso na construção de silos. Determinou-se as propriedades de fluxo (peso específico consolidado, angulo de atrito interno instantâneo, efetivo ângulo de atrito interno instantâneo, ângulo de atrito com a parede e coesão) e as propriedades físicas (granulometria e teor de umidade) dos produtos. Os valores experimentais foram confrontados com os prescritos pelas normas estrangeiras Eurocode 1 e ISO 11697. Com base nos resultados obtidos, verifica-se que as propriedades de ambos os produtos diferem dos valores propostos pelas referidas normas, estando alguns parâmetros superestimados em relação aos obtidos experimentalmente. Os valores obtidos poderão ser utilizados como parâmetros para elaboração de projeto de silo, predição de equipamentos e processamento do tipo de fluxo para as cultivares nacionais de milho e trigo, respeitando as especificidades intrínsecas as cultivares nacionais.

Palavras-chave: Milho; Trigo; Célula de cisalhamento de Jenike; Características de fluxo.

\begin{abstract}
The knowledge of the physical and flow properties of the products to be stored are essential for determining the type of flow in silos, hoppers and conveyors, enabling proper handling and processing of the product, in such a way as to obtain an economical, safe and durable structure, assuming a high interest in Brazil due to the fact that the country does not have a standard for dimensioning and designing these structures. This work sought to overcome this limitation by determining the physical and flow properties of two nationally expressive agricultural products (corn and wheat grains) that could be included in a future Brazilian standard for actions and flow in silos. To obtain the data, a direct translational shear device (TGS 70-140) and two wall surfaces were used: smooth and rough steel, as these are the materials with the greatest possibility of use in the construction of silos. The flow properties (consolidated specific gravity, instantaneous internal friction angle, effective instantaneous internal friction angle, wall friction angle and cohesion) and the physical properties (granulometry and moisture content) of the products were determined. The experimental values were compared with those prescribed by the foreign standards Eurocode 1 and ISO 11697. Based on the results obtained, it is verified that the properties of both products differ from the values proposed by those standards, with some parameters being overestimated in relation to those obtained experimentally . The values obtained can be used as parameters for the elaboration of a silo project, equipment prediction and processing of the type of flow for the national cultivars of corn and wheat, respecting the intrinsic specificities of the national cultivars. Keywords: Corn; Wheat; Jenike shear tester; Flow Characteristics.
\end{abstract}




\begin{abstract}
Resumen
El conocimiento de las propiedades físicas y de flujo de los productos a almacenar es fundamental para determinar el tipo de flujo en los silos, tolvas y transportadores, que permitan un correcto manejo y procesamiento del producto, de tal manera que se obtenga un rendimiento económico, seguro y estructura duradera, asumiendo un alto interés en Brasil debido a que el país no cuenta con un estándar para el dimensionamiento y diseño de estas estructuras. Este trabajo buscó superar esta limitación determinando las propiedades físicas y de flujo dos productos agrícolas de expresión nacional (granos de maíz y trigo) que podrían incluirse en un futuro estándar brasileño para acciones y flujo en silos. Para la obtención de los datos se utilizó un dispositivo de cizallamiento traslacional directo (TGS 70-140) y dos superficies de muro: acero liso y rugoso, ya que estos son los materiales con mayor posibilidad de uso en la construcción de silos. Se determinaron las propiedades de flujo (peso específico consolidado, ángulo de fricción interno instantáneo, ángulo de fricción interno instantáneo efectivo, ángulo de fricción de la pared y cohesión) y las propiedades físicas (granulometría y contenido de humedad) de los productos. Los valores experimentales se compararon con los prescritos por las normas extranjeras Eurocódigo 1 e ISO 11697. Con base en los resultados obtenidos, se verifica que las propiedades de ambos productos difieren de los valores propuestos por dichas normas, siendo algunos parámetros sobreestimados en relación a los obtenidos experimentalmente. Los valores obtenidos se pueden utilizar como parámetros para la elaboración de un proyecto de silo, predicción de equipos y procesamiento del tipo de flujo para los cultivares nacionales de maíz y trigo, respetando las especificidades intrínsecas de los cultivares nacionales.
\end{abstract}

Palabras clave: Maíz; Trigo; Probador de cizallamiento Jenike; Caracteristicas de flujo.

\title{
1. Introdução
}

A produção de grãos no Brasil representa um dos principais segmentos do setor agrícola em todo o mundo, sendo soja, milho e trigo os destaques na balança comercial com montantes que exigem grandes projetos de silos para armazenagem, com aplicação industrial nas mais diversas áreas de processamento (Baroni et al., 2017). De acordo com a Companhia Nacional de Abastecimento (Conab, 2021), a produção nacional de milho para 2021estima-se em torno de 106,4 milhões de toneladas, crescimento de 3,7\% sobre a produção de 2019/20. Em relação as culturas de inverno (aveia, canola, centeio, cevada, trigo e triticale) destaca-se o trigo, com estimativas de produção de 6,6 milhões de toneladas, número 3,3\% superior ao produzido em 2020 (Conab, 2021).

No projeto de silos, tremonhas e transportadores a determinação das propriedades do produto a se armazenar são fundamentais para compreensão do fluxo e cálculo das pressões que irão ocorrer durante as operações de carregamento, armazenamento e descarregamento, de tal modo que se obtenha uma estrutura econômica, segura e com durabilidade (AlonsoMiravalles et al., 2020), devendo-se realizá-la nas condições mais severas daquelas que podem ocorrer (Ripp et al., 2015; Ambrose et al., 2016). Os problemas que ocorrem na prática, são majoritariamente devidos a concepção de projetos inadequados juntos com a falta de conhecimento das relevantes propriedades físicas dos produtos armazenados e do fluxo.

Ainda não existem normas nacionais para regulamentar o projeto e construção de estruturas de armazenamento, o que faz com que os projetistas tenham que buscar no exterior tais normativas para consultar valores de propriedades físicas de produtos e coeficientes de atrito da parede com o produto, normas estrangeiras cujos parâmetros divergem e, além disso, não retratam as características intrínsecas aos grãos brasileiros (Fank, 2017).

Muitos métodos e equipamentos para determinação das propriedades dos materiais armazenados existem, nos quais as células de cisalhamento são os dispositivos mais empregados mundialmente (Ramírez-Gómez, 2016; Grudzień, et al., 2018; Jin et al., 2018; García-Triñanes et al., 2019; Macri et al., 2020), destacando a "Jenike Shear Cell” ou célula de cisalhamento de Jenike como um dos métodos mais aceitos para determinar as propriedades de fluxo e recomendado pela maioria das normas estrangeiras (Guo et al., 2018; Mallick et al., 2018; Meira et al., 2019).

A obtenção das propriedades de fluxo e o desenvolvimento dos critérios de projeto dependem do conhecimento do lugar geométrico da tensão de cisalhamento versus a tensão normal para o produto deslizando sobre si mesmo e sobre o material da parede do silo (Salehi et al., 2017; Malagalage et al., 2018). Sendo possível, por meio deste equipamento, a 
determinação das tensões sob as quais os produtos (coesivos ou não) estarão sujeitos durante o armazenamento, assim como as condições de fluxo preditas para acontecer no interior da estrutura.

As principais propriedades físicas dos produtos determinadas e utilizadas para o projeto de fluxo e estruturas de silos são: peso específico consolidado $(\gamma)$; granulometria; teor de umidade $(w)$; ângulo de atrito interno $\left(\phi_{\mathrm{i}}\right)$; efetivo ângulo de atrito interno $\left(\phi_{\mathrm{e}}\right)$; ângulo de atrito interno do produto com a parede $\left(\phi_{\mathrm{w}}\right)$ e coesão (C) (Stasiak et al., 2015; Calderón et al., 2017; Malagalage et al.,2018).

Diante do exposto, esta pesquisa objetivou a determinação das propriedades físicas e de fluxo para dois grãos expressivos na balança comercial brasileira, milho e trigo, utilizando a técnica da célula de cisalhamento de Jenike, visando contribuir com a futura norma brasileira de ações e fluxo em silos.

\section{Metodologia}

\subsection{Localização}

A pesquisa foi desenvolvida no Laboratório de Construções Rurais e Ambiência (LaCRA) pertencente ao Centro de Tecnologias e Recursos Naturais da Universidade Federal de Campina Grande (CTRN/UFCG), Campina Grande/PB, entre os meses de dezembro de 2020 e fevereiro de 2021.

\subsection{Produtos utilizados}

Como o escopo da pesquisa consistiu em estudar a armazenagem em silos, optou-se por utilizar os produtos empregados de modo representativo no meio agrícola brasileiro, sendo escolhidos trigo e milho em grãos, ambos fornecidos por uma empresa nacional de armazenamento. Caracteriza-se, portanto, em pesquisa de caráter experimental (Fonseca, 2002; Gil, 2007; Gerhardt \& Silveira, 2009) com descrição da metodologia empregada nos subtópicos seguintes.

\subsection{Determinação das propriedades de fluxo}

Para a determinação das propriedades de fluxo dos produtos granulares adotou-se o procedimento recomendado pela British Materials Handling Board (1985), utilizando a máquina de cisalhamento por translação TSG 70-140 (Jenike Shear Cell) (Figura 1) permitindo construir gráficos de tensão normal versus cisalhamento $(\sigma, \tau)$ (Figura 2). Com isso, foi possível traçar círculos de tensões de Mohr responsáveis por determinar a Tensão Principal de Consolidação $\left(\sigma_{1}\right)$ e a Tensão Não Confinada de Deslizamento $\left(\sigma_{\mathrm{c}}\right)$, permitindo a obtenção das propriedades: ângulo de atrito interno $\left(\emptyset_{\mathrm{i}}\right)$, ângulo efetivo de atrito interno $\left(\emptyset_{\mathrm{e}}\right)$ e coesão $(\mathrm{C})$ dos produtos para os diferentes níveis de carga adotados (Tabela 1).

Figura 1. Aparelho de cisalhamento direto - Jenike Shear Cell.

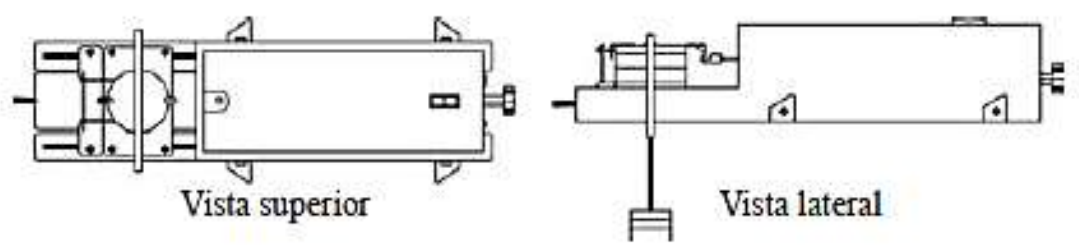

Fonte: Lopes Neto e Nascimento (2013). 
Figura 2. Fases do teste de cisalhamento direto para obtenção do lugar geométrico de deslizamento.

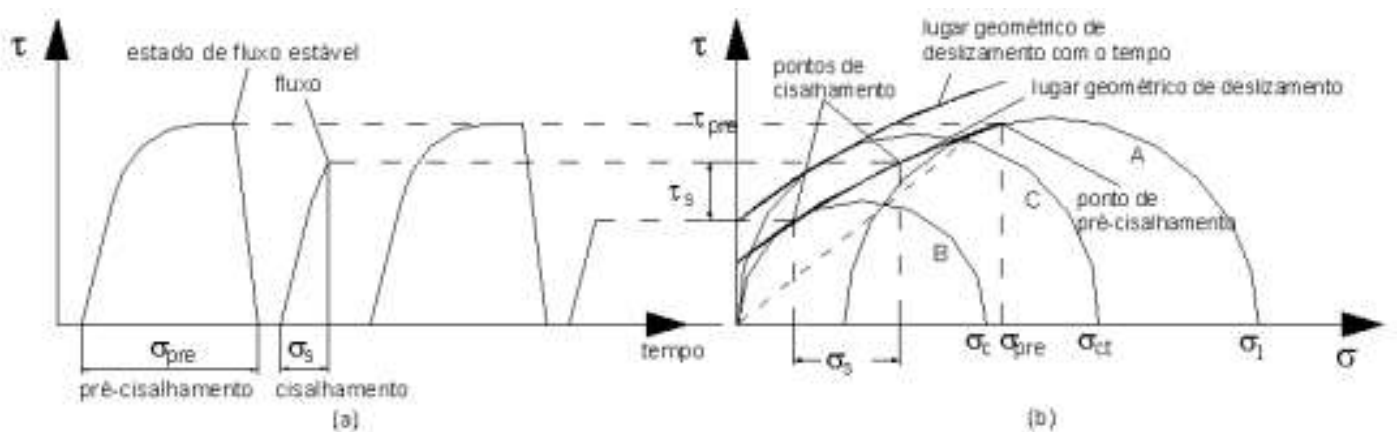

Fonte: Palma (2005).

Tabela 1. Níveis de carga normal empregadas nos ensaios.

\begin{tabular}{cccc}
\hline Pré-Cisalhamento $(\mathrm{N})$ & \multicolumn{3}{c}{ Cisalhamento $(\mathrm{N})$} \\
\hline 100 & 70 & 50 & 35 \\
70 & 50 & 35 & 20 \\
50 & 35 & 20 & 10 \\
\hline
\end{tabular}

Fonte: Autores.

Para a determinação do ângulo de atrito com a parede $\left(\emptyset_{\mathrm{w}}\right)$, adotou-se as recomendações da British Materials Handling Board (1985), utilizando-se o mesmo equipamento e a mesma célula de cisalhamento, substituindo-se apenas o anel inferior pela amostra do material da parede, sendo os níveis de cargas iguais a $50 \mathrm{~N}, 40 \mathrm{~N}, 30 \mathrm{~N}, 20 \mathrm{~N}, 10 \mathrm{~N}$ e $4,4 \mathrm{~N}$. As superfícies utilizadas nos ensaios foram as paredes de aço liso e rugoso por serem os materiais com maior possibilidade de uso na construção de silos, tanto em níveis de fazenda como industriais. O peso específico $(\gamma)$ e todos os ângulos de atrito foram apresentados com seus limites superior e inferior para que os projetistas possam utilizar o método dos estados limites para o cálculo das pressões atuantes no corpo e na tremonha dos silos.

As propriedades de fluxo obtidas através dos ensaios no aparelho de cisalhamento Jenike Shear Cell foram comparadas com valores estabelecidos pelas normas estrangeiras Eurocode1 (EN 1991- 4:2006) e ISO 11697 (ISO 11697:1995) para milho e trigo.

\subsection{Determinação das propriedades físicas}

As propriedades físicas determinadas foram teor de umidade $(w)$ e granulometria. $\mathrm{O}$ teor de umidade $(w)$ dos grãos foi encontrado pela pesagem de uma amostra de $10 \mathrm{~g}$ de cada produto antes e após a secagem em estufa a $105^{\circ} \mathrm{C}$ por $24 \mathrm{~h}$. As amostras foram analisadas em triplicata para cada produto sendo o resultado final expresso em base úmida $\left(w_{b}\right)$.

A granulometria foi definida por peneiramento, colocando-se $500 \mathrm{~g}$ de cada produto em jogo de peneiras padrão ABNT $(6,35 ; 4,76 ; 4,00 ; 2,36 ; 1,40 ; 1,00 \mathrm{~mm})$ e agitador elétrico, durante $05 \mathrm{~min}$. A classificação efetuou-se baseada na proposta de Calil Júnior (1984), em função das dimensões do diâmetro das partículas (Tabela 2).

Tabela 2. Classificação do produto armazenado quanto à granulometria.

\begin{tabular}{cc}
\hline Diâmetro (D) das partículas sólidas & Classificação do produto armazenado \\
\hline $\mathrm{D}>0,42 \mathrm{~mm}$ & Granulares \\
$0,42 \leq \mathrm{D} \leq 0,149 \mathrm{~mm}$ & Pulverulentos coesivos \\
$0,149<\mathrm{D} \leq 0,074 \mathrm{~mm}$ & Pulverulentos coesivos finos \\
$\mathrm{D}<0,074 \mathrm{~mm}$ & Pulverulentos coesivos extra finos \\
\hline
\end{tabular}

Fonte: Calil Júnior (1984). 


\section{Resultados e Discussão}

\subsection{Propriedades de fluxo dos produtos analisados}

As propriedades de fluxo dos produtos na condição instantânea são apresentadas na Tabela 3. As propriedades peso específico consolidado $(\gamma)$, ângulo de atrito interno $\left(\varnothing_{\mathrm{i}}\right)$, ângulo efetivo de atrito interno $\left(\varnothing_{\mathrm{e}}\right)$ e ângulo de atrito com a parede $\left(\varnothing_{w}\right)$ são apresentados em seus valores máximos e mínimos possibilitando, assim, o projeto de silos através do método dos estados limites, de modo a obter-se a combinação mais desfavorável de carregamento na estrutura, considerando as possíveis mudanças das propriedades do produto com o tempo e as variações das amostras.

Em termos de propriedades, as normas estrangeiras ISO e Eurocode1 não apresentam o efetivo ângulo de atrito interno $\left(\varnothing_{\mathrm{e}}\right)$ e ângulo de atrito com a parede $\left(\varnothing_{\mathrm{w}}\right)$. Elas apresentam, em tabelas próprias, os valores da relação entre pressões, $\mathrm{K}$, e do coeficiente de atrito com a parede $(\mu)$.

Tabela 3. Propriedades de fluxo dos produtos granulares

\begin{tabular}{|c|c|c|c|c|c|c|c|c|c|c|c|}
\hline \multirow[t]{3}{*}{ Produtos } & \multirow{2}{*}{\multicolumn{2}{|c|}{$\begin{array}{c}\gamma \\
\left(\mathrm{kN}^{-3}\right)\end{array}$}} & \multirow{2}{*}{\multicolumn{2}{|c|}{$\begin{array}{l}\emptyset_{\mathrm{i}} \\
\left(^{\circ}\right)\end{array}$}} & \multirow{2}{*}{\multicolumn{2}{|c|}{$\begin{array}{l}\emptyset_{\mathbf{e}} \\
\left(^{\circ}\right)\end{array}$}} & \multicolumn{4}{|c|}{$\emptyset_{w}$} & \multirow[t]{3}{*}{$\begin{array}{c}\mathbf{C} \\
(\mathrm{Pa})\end{array}$} \\
\hline & & & & & & & \multicolumn{2}{|c|}{ Aço liso $\left(^{\circ}\right)$} & \multicolumn{2}{|c|}{ Aço rugoso $\left({ }^{\circ}\right)$} & \\
\hline & Inf. & Sup. & Inf. & Sup. & Inf. & Sup. & Inf. & Sup. & Inf. & Sup. & \\
\hline Milho & 7,4 & 7,6 & 26 & 32 & 30 & 35 & 10,5 & 12,0 & 17,8 & 20,9 & 642,7 \\
\hline Trigo & 8,1 & 8,2 & 26 & 31 & 29 & 31 & 7,6 & 11,0 & 15,2 & 18,2 & 276,3 \\
\hline
\end{tabular}

$\gamma$ - Peso específico consolidado; $\varnothing$ - Ângulo de atrito interno; $\emptyset_{\mathrm{e}}$ - Efetivo ângulo de atrito interno; $\emptyset_{\mathrm{w}}$ - Ângulo de atrito com a parede; C - Coesão. Fonte: Autores.

O milho apresentou valores para o peso específico consolidado $(\gamma)$, ligeiramente inferiores aos das normas ISO 11697 e Eurocode1, cujos valores recomendados são de 7,5 e $8,5 \mathrm{kN} \mathrm{m}^{-3}$ para os limites inferior e superior, respectivamente. Para o trigo, enquanto a norma Eurocode1 recomenda valores inferiores e superiores de 8,0 e 9,0 $\mathrm{kN} \mathrm{m}^{-3}$ respectivamente, o código normativo ISO 11697 sugere 9,0 e $10 \mathrm{kN} \mathrm{m}^{-3}$, apresentando-se dentro da faixa estabelecida pela norma Eurocode $1 \mathrm{e}$ fora dos limites sugeridos pela ISO.

O peso específico dos produtos armazenados apresenta correlação com a sua umidade, bem como com o tipo de carregamento, taxa e a altura de queda durante este processo, ainda, com o tempo de armazenamento e com as sobrepressões que se desenvolvem (Fürll \& Hoffmann, 2015). Esses são os principais motivos pelos quais seus valores divergem entre pesquisas e normas, a exemplo dos grãos de trigo analisados, que divergiram dos limites superiores normativos em torno de 6\% para Eurocode e 22\% para ISO. Conforme Calil Júnior (1990), não há relação direta entre o peso específico com a predição do fluxo, contudo, sua determinação é essencial pois constitui parâmetro importante para cálculo das pressões atuantes em paredes e tremonhas de silos (Jager et al. 2015) além da estimativa da capacidade do silo (Stasiak et al., 2015).

Para o ângulo de atrito interno $\left(\emptyset_{\mathrm{i}}\right)$ houve uma variação entre os limites inferior e superior em torno de $23 \%$ para o milho e $19 \%$ para o trigo. Apenas a Eurocode1 indica valor médio de ângulo de atrito, sendo de $30^{\circ}$ para o trigo e $31^{\circ}$ para o milho, as médias encontradas na presente pesquisa foram de $28,5^{\circ}$ para o trigo e $29^{\circ}$ para o milho. Pode-se observar que os resultados das formulações normativas reproduzem valores divergentes, que consequentemente vão refletir nos valores de pressões teóricas. Grande variação nos valores das propriedades também são observados na análise de outras pesquisas desenvolvidas tal como em Moya et al. (2013), foram obtidos experimentalmente os seguintes valores para algumas propriedades de grãos de milho: $\gamma_{\text {inf }}=7,5 \mathrm{kN} \mathrm{m}^{-3} ; \gamma_{\text {sup }}=12,63 \mathrm{kN} \mathrm{m}^{-3}$ e $\emptyset_{\text {i-médio }}=25^{\circ}$ e para Fank et al. (2018) os resultados 
para grãos de milho foram: $\gamma_{\text {inf }}=7,5 \mathrm{kN} \mathrm{m}^{-3} ; \gamma_{\text {sup }}=7,54 \mathrm{kN} \mathrm{m}^{-3} ; \emptyset_{\text {i-inf }}=19^{\circ} ; \emptyset_{\text {i-sup }}=28^{\circ}$ e $\emptyset_{\text {e-inf }}=25^{\circ}$ e $\emptyset_{\text {e-sup }}=32,5^{\circ}$. Em relação ao trigo, Horabik et al. (2016) obtiveram $\gamma=12,5,5 \pm 6 \mathrm{kN} \mathrm{m}^{-3} \mathrm{e} \emptyset_{\mathrm{i}}=24,6 \pm 0,8^{\circ}$; Cheng et al. (2012) relataram $\emptyset_{\mathrm{i}}$ variando de 21,21 a $37,94^{\circ}$.

O efetivo ângulo de atrito interno $\left(\emptyset_{\mathrm{e}}\right)$ do milho para Lopes Neto \& Nascimento (2013) apresentou limites inferior e superior de 23,9 e $25,0^{\circ}$, respectivamente, sendo encontrados valores 25,5 e $40 \%$ superiores na presente pesquisa para o mesmo produto. Fank et al. (2018) obtiveram uma variação de 25,0 a 32,5 do Øe ao analisarem grãos de milho. Na maioria das teorias sobre as relações das pressões laterais, o fator $\mathrm{k}$ é determinado apenas com o conhecimento do efetivo ângulo de atrito interno sendo o ângulo de atrito com a parede considerado em apenas algumas formulações (Lopes Neto et al., 2014) evidenciando a importância de determinação deste parâmetro e a variação existente entre diferentes cultivares do mesmo produto. $\mathrm{O}$ trigo apresentou uma variação de aproximadamente $7 \%$ entre os valores limites do efetivo ângulo de atrito interno, estando o limite superior em torno de $13 \%$ abaixo do valor encontrado para o milho, nas mesmas condições de ensaio.

Analisando os resultados dos ângulos de atrito do produto com a parede (Tabela 3), percebe-se que para os materiais aço liso e rugoso, os menores valores registrados foram para o trigo, indicando que para o mesmo material de parede, este deslizará com mais facilidade quando comparado ao milho. Os valores registrados para aço rugoso foram superiores ao aço liso, para ambos os produtos, em virtude deste material ser mais áspero, quando comparado ao aço liso, com isso ocorrerá maior força de compressão vertical nas paredes dos silos.

A diferença entre o limite inferior e superior do ângulo de atrito com a parede $\left(\varnothing_{\mathrm{w}}\right)$, foi baixa para ambos os produtos, ocorrendo em torno de $3^{\circ}$ para aço rugoso. Estes resultados poderão ser empregados para o dimensionamento de equipamentos de transporte, como também para o cálculo das ações nas paredes e fundo dos silos, pelo fato de serem os principais tipos de materiais empregados na construção de silos e equipamentos.

Para coesão (C) nota-se que o valor absoluto para o milho foi superior ao trigo, fato este corroborado pelos maiores valores obtidos para o ângulo de atrito interno do milho; possivelmente em razão da maior quantidade de pó presente na amostra, entretanto, tal diferença na coesão pouco afeta a condição de fluxo para ambos os produtos sendo previsto um fluxo com característica livre, sem dificuldade de esvaziamento do silo. Comportamento semelhante foi observado por Lopes Neto \& Nascimento (2013) que obtiveram maior coesão para milho em grãos (400,6 Pa) quando comparado ao farelo de soja (128,0 Pa). Calil Junior \& Cheung (2007), afirmam que um dos fatores que contribuem para a coesão é a presença de pó.

\subsection{Propriedades físicas}

\subsubsection{Granulometria e teor de umidade $(w)$}

Através dos ensaios de granulometria, observou-se que o maior valor de percentual retido acumulado para o milho foi de $83 \%$ para a peneira de malha $6.35 \mathrm{~mm}$ e para o trigo cerca de $60 \%$ para peneira de malha $1.4 \mathrm{~mm}$ e os $40 \%$ restantes na malha de $2.8 \mathrm{~mm}$. Conforme classificação dos produtos sólidos em função das dimensões do diâmetro das partículas proposta por Calil Junior (1984), pode-se considerar milho e trigo como produtos de característica granular, pois a granulometria de ambos resultou em valor superior a $1 \mathrm{~mm}$. A granulometria caracteriza uma das propriedades que exerce influência direta no padrão de fluxo, determinando o tipo de escoamento (Jager et al., 2015). Produtos classificados como granulares são geralmente de fluxo livre, já os produtos de granulometria fina comumente apresentam menor fluidez devido à coesão (Siliveru et al., 2017).

Mellmann et al. (2013) estudaram o efeito do formato e granulometria de diferentes produtores granulares (trigo, cevada, aveia e milho) nas propriedades de fluxo. Os autores constataram aumento da fluidez para a maior faixa granulométrica, pelo fato de apresentarem propriedades não-coesivas. No quesito formato, os resultados revelaram que a fluidez dos grãos triturados diminuiu quanto mais a formato das partículas distanciavam-se da forma esférica. 
De acordo com os testes para a determinação do teor de umidade (w), o milho e o trigo encontravam-se com 11,1\% e 11,4\%b.u., respectivamente. Souza et al. (2015) afirmam que para o armazenamento seguro, os grãos devem apresentar entre 13 e $14 \%$ de umidade em base úmida (b.u.), constituindo uma propriedade que afeta diretamente a densidade, durabilidade e capacidade de fluir do produto (Ripp et al., 2015). Costa et al. (2014) determinaram as propriedades mecânicas e de fluxo de produtos granulares (grãos de arroz e milho triturado) com teores de umidade de 10, 12 e $14 \%$ e de produto pulverulento (farinha de mandioca) com teores umidade de 10 e $12 \%$. Os autores constataram que o ângulo de atrito interno $\left(\emptyset_{\mathrm{i}}\right.$ ) e efetivo ângulo de atrito interno $\left(\emptyset_{\mathrm{e}}\right)$ para todos os produtos estudados, tiveram um acréscimo em função do aumento do teor de umidade.

O aumento da umidade associado com o tempo de armazenamento dificulta a fluidez, aumentando a possibilidade de ocorrência de obstruções de fluxo (Mitra et al., 2017). Para Nascimento (1996) sob elevados teores de umidades e condições atmosféricas adversas, os grãos podem sofrer fermentação, adquirindo resistência e deixando de ser de fluxo livre.

\section{Considerações Finais}

A análise comparativa realizada dos resultados experimentais com as principais normas estrangeiras mostrou a existência de diferenças entre os valores obtidos, considerando a combinação mais desfavorável das propriedades dos produtos (limites inferior e superior), denotando-se a importância da realização de ensaios para caracterização dos produtos. Como o Brasil não possui uma norma que regulamenta o projeto de silos e de fluxo, esses dados poderão ser usados para o dimensionamento de silos e a predição do fluxo para a obtenção de projetos mais seguros e econômicos.

Visando ao aprofundamento nas pesquisas das propriedades físicas e de fluxo sugere-se para futuros trabalhos a determinação das propriedades de produtos granulares em função do tempo de consolidação, tais procedimentos podem trazer substancial contribuição a uma futura e adequada padronização dos projetos e dimensionamentos dos silos e, desta forma, mitigar os problemas de colapsos destas estruturas.

\section{Agradecimentos}

Ao Instituto de Ciências Agrárias e Ambientais (ICAA) da Universidade Federal de Mato Grosso - Campus Sinop, por ter concedido licença para realização do doutorado ao primeiro autor.

Ao Programa de Pós-Graduação em Engenharia Agrícola da Universidade Federal de Campina Grande - Campus Campina Grande pelo apoio na realização deste trabalho.

\section{Referências}

Alonso-Miravalles, L., Zannini, E., Bez, J., Arendt, E. K. \& O'Mahony, J. A. (2020). Physical and flow properties of pseudocereal-based protein-rich ingredient powders. Journal of Food Engineering, 281: 109973.

Ambrose, R. P. K., Jan, S. \& Siliveru, K. (2016). A review on flow characterization methods for cereal grain-based powders. Journal of Food Measurement and Characterization, 96: 359-364.

Baroni, G. D., Benedeti, P. H. \& Seidel, D. J. (2017). Cenários prospectivos da produção e armazenagem de grãos no Brasil. Revista Thema, 14(4): 55-64.

BMHB - British Materials Handling Board. Draft code of practice for the design of silos, bins, bunkers and hoppers. BMHB, 1985. 143p.

Calderón, C. A., Olivares, M. C. V., Uñac, R. O. \& Vidales, A. M. (2017). Correlations between flow rate parameters and the shape of the grains in a silo discharge. Powder Technology, 320: 43-50.

Calil Júnior, C. (1984). Sobrepeciones em las paredes de los silos para almacenamiento de productos pulverulents cohesivos. Tese de Livre Docência, Escola de Engenharia de São Carlos, Universidade de São Paulo.

Calil Júnior, C. (1990). Recomendações de fluxo e de cargas para o projeto de silos verticais. Tese (Livre Docência) - Escola de Engenharia de São Carlos, Universidade de São Paulo. 
Calil Júnior, C., \& Cheung A. B. (2007) Silos: Pressões, fluxo, recomendações para o projeto e exemplos de cálculo. EESC. 232p.

Cheng, X. D., Lu, L. L. \& Shi, C. X. (2012). The experimental research on friction properties of wheat. Journal of the Chinese Cereals and Oils Association, 27(4):15-19.

CONAB - Companhia Nacional de Abastecimento (2021). Acompanhamento safra brasileira de grãos, v.8- Safra 2020/21, n. 4 - Quarto levantamento, 1-85. https://www.conab.gov.br/info-agro/safras/graos/boletim-da-safra-de-graos.

Costa, C. A. da, Lopes Neto, J. P., Nascimento, J. W. B. do, Diniz, M. J. \& Silva, V. R. da. (2014). Propriedades mecânicas e de fluxo de produtos agroindustriais. Revista Brasileira de Engenharia Agrícola e Ambiental, 18:774-780.

EN 1991-4: EUROCODE 1. Actions on structures - Part 4: Silos and tanks. European Committee for Normalisation. 108 p.

Fank, M. Z., Nascimento, J. W. B. do, Cardoso, D. L., Meira, A. S. \& Willrich, F. L. (2018). Pressões verticais e força de fricção compressiva em um grande silo. Engenharia Agrícola, 38 (4): 498-503.

Fank, M. Z. (2017). Pressões em silos verticais cilíndricos metálicos: determinação experimental e cálculos teóricos por normas estrangeiras. Campina Grande: UFCG. 170p. Tese Doutorado.

Fank, Marivone Z., Nascimento, José W. B. do, Cardoso, Décio L., Meira, Ariadne S., \& Willrich, Fábio L. (2018). Vertical pressures and compressive friction force in a large silo. Engenharia Agrícola, 38(4): 498-503.

Fonseca, J. J. S. Metodologia da pesquisa científica. UEC, 2002. Apostila.

Fürll, C. \& Hoffmann, T. (2015). Assessment of the flow properties of crushed grain products depending on the granulometric condition. Agricultural Engineering International: CIGR Journal, 17(4): 377-386.

García-Triñanes, P., Luding, S. \& Shi, H. (2019). Tensile strength of cohesive powders. Advanced Powder Technology, 30(12): 2868-2880.

Gil, A. C. Como elaborar projetos de pesquisa. (4a ed.), Atlas, 2007.

Gerhardt, T. E. \& Silveira, D. T. Métodos de pesquisa. Editora da UFRGS, 2009.

Grudzień, K., Chaniecki, Z. \& Babout, L. (2018). Study of granular flow in silo based on electrical capacitance tomography and optical imaging. Flow Measurement and Instrumentation, 62: 186-195.

Guo, Z., Shan, Z., Du, D., Zhao, M. \& Zhang, M. (2018). Experimental investigation on the flow properties of sand granules in the process of sand mold printing. Rapid Prototyping Journal, 24(9): 1599-1608.

Horabik, J., Parafiniuk, P. \& Molenda, M. (2016). Experiments and discrete element method simulations of distribution of static load of grain bedding at bottom of shallow model silo. Biosystems Engineering, 149: 60-71.

International Organization for Standart. ISO 11697. Bases for design of structures: Loads due to bulk materials. Switzerland: International Standard. London, 2012 .

Jager, P. D., Bramante, T. \& Luner, P. E. (2015). Assessment of pharmaceutical powder flowability using shear cell-based methods and application of Jenike's methodology. Journal of Pharmaceutical Sciences, 104(11): 3804-3813.

Jin, Y., Lu HF, Guo, X. L. \& Gong, X. (2018). The effect of water addition on the surface energy, bulk and flow properties of lignite. Fuel Processing Technology, 176: 91-100.

Lopes Neto, J. P. \& Nascimento, J. W. B. do (2013). Características de fluxo e projeto de tremonhas cônicas em silos verticais. Revista Brasileira de Engenharia Agrícola e Ambiental, 17(3): 339-345.

Lopes Neto, J. P. \& Nascimento, J. W. B. do (2013). Características de fluxo e projeto de tremonhas cônicas em silos verticais. Revista Brasileira de Engenharia Agrícola e Ambiental,17(3):339-345.

Lopes Neto, J. P., Nascimento, J. W. B. do \& Fank, M. Z. (2014). Forças verticais e de atrito em silos cilíndricos com fundo plano. Revista Brasileira de Engenharia Agrícola e Ambiental, 18(6):652-657.

Macri, D., Chirone, R., Salehi, H., Sofia, D., Materazzi, M., Barletta, D., Lettieri, P. \& Poletto, M. (2020). Characterization of the bulk flow properties of industrial powders from shear tests. Processes, 8(5): 540.

Malagalage, A., Ratnayake, C., Saasen, A., Thomassen, T. \& Von-Hafenbrädl, F. O. (2018). Flow properties of drill cuttings with varying drilling fluid content using jenike shear testing. Chemical Engineering \& Technology, 41(8): 1544-1550.

Mallick, S. S., Rohilla, L., Garg, V. \& Setia, G. (2018). Modeling flow properties of fine dry powders using particle morphological properties and its effects on geometry of fly ash evacuation hoppers. Particulate Science \& Technology, 36(4): 464-472.

Meira, A. S., Mota, E. L., Bandeira, D. J. A., Silva, V. R. \& Silva, L. A. (2019). Propriedades de fluxo e pressões para projeto de silo vertical armazenador de açúcares. Revista Engenharia na Agricultura - Reveng, 27(2): 104-110.

Mellmann, J., Hoffmann, T. \& Fürll, C. (2013). Flow properties of crushed grains as a function of the particle shape. Powder Technology, 249:269-273.

Mitra, H., Pushpadass, H. A., Franklin, M. E.E., Ambrose, R. P. K., Ghoroi, C. \& Battula, S. N. (2017). Influence of moisture content on the flow properties of basundi mix. Powder Technology, 312:133-143. 
Research, Society and Development, v. 10, n. 10, e234101018754, 2021

(CC BY 4.0) | ISSN 2525-3409 | DOI: http://dx.doi.org/10.33448/rsd-v10i10.18754

Moya, M., Aguado, P. J. \& Ayuga, F. (2013). Mechanical properties of some granular agricultural materials used in silo design. Intitute of Agrophysics, 27:181-193.

Nascimento, J. W. B. do. (1996). Estudos de silos metálicos prismáticos para fábricas de ração. Tese Doutorado USP, 222p.

Palma, G. (2005). Pressões e fluxos em silos esbeltos ( $/ d \geq l, 5)$. Escola de Engenharia de São Carlos, Universidade de São Paulo. Dissertação de Mestrado.

Ramírez-Gómez, Á. (2016). Research needs on biomass characterization to prevent handling problems and hazards in industry. Particulate Science \& Technology, 34(4): 432-441.

Ripp, M., Debele, Z. A. \& Ripperger, S. (2015). Determination of Bulk Flow Property of tef Flour and Seed and Design of a Silo. Particulate Science \& Technology, 33(5): 494-502.

Salehi, H., Barletta, D. \& Poletto, M. (2017). A comparison between powder flow property testes. Particuology, 32:10-20.

Siliveru, K., Ambrose, R. P. K. \& Vadlani, P. V. (2017). Significance of composition and particle size on the shear flow properties of wheat flour J. Sci. Food Agric., 97:2300-2306.

Souza, G. F. M. V., Miranda, R. F., Barrozo, M. A. S. (2015). Soybean (Glycine max L. Merrill) Seed Drying in Fixed Bed: Process Heterogeneity and Seed Quality.Drying Technology, 33(14): 1779-1787.

Stasiak, M., Molenda, M., Bańda, M. \& Gondek, E. (2015). Mechanical properties of sawdust and woodchips. Fuel, 159: 900-908. 